http://jmscr.igmpublication.org/home/ ISSN (e)-2347-176x ISSN (p) 2455-0450 crossref DOI: https://dx.doi.org/10.18535/jmscr/v8i7.70

\author{
Journal Of Medical Science And Clinical Research

\title{
To compare the efficacy and safety of sublingual and vaginal dose of Misoprostol for induction of labor in term viable pregnancies
}

\author{
Authors \\ Dr Shweta Patel ${ }^{1}$, Dr Shabd Yadav', Dr Kalpana Yadav ${ }^{3 *}$ \\ ${ }^{1}$ Assistant Professor, Department of Obstetrics \& Gynecology, AIIMS Bhopal (M.P.), India \\ ${ }^{2}$ Associate Professor, Department of Pediatrics, SSMC Rewa (M.P.), India \\ ${ }^{3}$ Professor \& Head, Department of Obstetrics \& Gynecology, SSMC Rewa (M.P.), India \\ *Corresponding Author \\ Dr Kalpana Yadav \\ Professor \& Head, Department of Obstetrics \& Gynecology, SSMC Rewa (M.P.), India
}

\begin{abstract}
Objective: To compare the efficacy and safety of misoprostol by sublingual and vaginal route for induction of labor in term viable pregnancies.

Material and Methods: This prospective study was conducted on 200 women, who presented with indication of induction of labor. After taking informed consent cases were randomly divided into sublingual and vaginal group with 100 cases in each. Starting dose of misoprostol for induction in primigravida was $50 \mu \mathrm{g}$ and in miultigravida was $25 \mu \mathrm{g}$ followed by $25 \mu \mathrm{g}$ if required, up to maximum of 5 doses. Primary outcome was to determine efficacy of drug in term of total vaginal deliveries after induction and to determine safety in view of total number of cesarean section and fetal outcome. Secondary outcome was to compare total dose, number of doses, induction delivery interval, antepartum complications and fetal outcome in both groups.

Result: Total number of successful vaginal deliveries were more in sublingual group (87\%). Significant number of primigravidae in sublingual group delivered with single dose of 50 $\mathrm{g}$ misoprostol compare with vaginal group $(56.89 \%$ in $s / l \mathrm{v} / \mathrm{s} 32.69 \%$ in $\mathrm{p} / \mathrm{v}$ group). Induction delivery interval, oxytocin augmentation, meconium stained liquor, abnormal uterine action, total number of cesarean sections all were less in sublingual group than vaginal group. No significant difference was seen in neonatal outcome.

Conclusion: Sublingual route of misoprostol has better efficacy than vaginal route of misoprostol for induction of labor.

Keywords: Misoprostol, Induction of labor, Meconium stained liquor.
\end{abstract}

\section{Introduction}

Induction of labor is widely carried out all over the world in cases, in which continuation of pregnancy is hazardous to the mother and/or her fetus. Labor induction in women with live fetus at term remains a major challenge in modern 
obstetrics. In the recent past misoprostol, the wonder drug which used for management of PPH is still under trial for labor induction with various routes and doses. It has some potential advantages as compared with $\mathrm{PGE}_{2}$ i.e. it is inexpensive, stable at room temperature, easy to administer and may be given orally. ${ }^{1}$ Initially it was used as a vaginal dose $(50 \mu \mathrm{g})$ every 2 hourly, up to maximum total dose of $600 \mu$ gbut it is associated with higher risk of uterine hyper- stimiulation. ${ }^{2}$ Since then lower dose have been proposed to reduce adverse effect though with other routes. Ever since pharmacokinetic studies show that sublingual and oral misoprostol produces earlier and higher peak plasma concentration of misoprostol acid than vaginal or rectal misoprosto. ${ }^{3}$ Women prefer to use misoprostol orally or sublingually instead of vaginal route, claiming that oral route is more convenient and offer greater privacy. ${ }^{4}$

In spite of different doses and routes of administered (sublingual, oral and vaginal), ideal doses and mode of administration still remain to be controversial. Thus, the present study is being conducted to compare efficacy and safety of sublingual and vaginal route of misoprostol for induction of labor and for establishing the best route and best dose of drug keeping in mind fetal and maternal risk.

\section{Aim}

To compare the efficacy and safety of misoprostol by sublingual and vaginal route for induction of labor.

\section{Objectives}

1. To study various demographic data like booking status, age, gravidity and various indications of induction.

2. To determine safe dose required for induction establishment.

3. To determine total dose, number of doses and induction delivery interval required for safe vaginal delivery.
4. To determine successful induction in term of vaginal deliveries within 12hours/ 24hours of initiation of labor.

5. To determine safety of drugs by total number of caesarean section and fetal outcome.

\section{Material and Methods}

The present study was conducted on 200 women, who presented with indication of induction of labor in department of Obstetrics and Gynecology, Shyam Shah Medical College and associated Gandhi Memorial Hospital, Rewa (M. P.) from July 2009 to September 2010.

Women with $\geq 37$ weeks of gestation with varied parity after taking informed consent following exclusion/inclusion criteria were taken in the study.

\section{Exclusion Criteria}

1. Parity $\geq 4$, Recurrent abortions $\geq 2$.

2. Known hypersensitivity to use of prostaglandin.

3. Previous caesarean delivery or other type of uterine surgery.

4. Need for immediate delivery (such as ominous FHR, active uterine bleeding).

5. Severe oligohydramnios (AFI $<5 \mathrm{~cm}$ by USG), Severe IUGR, Chorioamnionitis, Cephalopelvic disproportion.

\section{Inclusion Criteria}

1. Single live pregnancy in cephalic presentation

2. Normal FHR tracing

3. Unfavorable cervix (Bishop score <6)

4. Pregnant woman with any of the indication for induction of labor :-

a. Prolonged pregnancy ( $\geq 40$ weeks of gestation)

b. Prelabor rupture of membrane

c. Gestational/chronic hypertension.

d. IUGR

e. Oligohydramnios (AFI $6 \pm 1 \mathrm{~cm}$ )

After selection, detailed obstetric history complete physical and obstetric examination was done. Gestational age and AFI was assessed by 
ultrasonography. Cases were randomly put in either of the two groups with 100 cases in each:Group A - sublingual group (s/l). Group B Vaginal group (p/v).

Starting dose of misoprostol in primigravida was $50 \mu \mathrm{g}$ (half of $100 \mu \mathrm{g}$ )and in miultigravida was $25 \mu \mathrm{g}$, further regimen was as follows:

a) If uterine contractions were adequate, no further action was taken;

b) If uterine contractions were inadequate and/or progress was inadequate (cervical dilatation less than $1 \mathrm{~cm}$ per hour), $25 \mu \mathrm{g}$ misoprostol was subsequently given at 4 hours interval up to maximum 5 doses.

A watchful monitoring of FHR and uterine contraction was done every 15 minutes and later at regular intervals. Once cases entered in active labor, further augmentation with oxytocin was required only in cases with ineffective contractions (if the frequency of contractions was $<3$ per 10 minutes, or the contraction pattern was dysfunctional) oxytocin was administered not earlier then 4 hour after the last misoprostol dose starting at $1 \mathrm{miu} / \mathrm{minute}$ and increased by 1 miu/minute every 15 minute until adequate contractions persisted. Cases of abnormal uterine action (tachysystole, hypertonus or hyperstimiulation) was managed by intrauterine resuscitation (which included stopping the oxytocin infusion, maternal repositioning, hydration and oxygen administration) and/or injection Terbutaline. In case of fetal distress (FHR $<100$ minute) or cases not responding to injection Terbutaline were managed by emergency caesarean section.

An improvement of Bishop's score by 4 points from the original score, was taken as successful induction and If patient didn't respond to the drug at the end of protocol were consider as failed medical induction and taken for caesarean section. Fetal outcome was noted on the basis of Apgar score at 1 minute and 5 minutes. Resuscitation/NICU care was documented accordingly and followed for 2 days. Resuscitation was defined as the need for positive pressure ventilation or intubation. Mother and baby monitored for at least 3 days before discharge from hospital.

The primary outcome measures were caesarean section as a measure of safety, and failure to achieve vaginal delivery in 24 hours as a measure of clinical effectiveness. Secondary outcome measures included intrapartum events, uterine activity, maternal adverse effects and maternal and neonatal complications.

The results were analyzed by statistically modified ' $t$ ' test. Statistical significance was assigned to $\mathrm{P}$ values $<0.05$.

\section{Results}

Total 200 cases were randomized for the study and allocated into two groups with 100 cases in each. As shown in Table 1, in the present study maximum women $(59.5 \%)$ were unbooked and belonged to 20-25yr age group (76\%) and majorities $(63 \%)$ of women were primigravidae with Modified Bishop's score $\leq 3$ prior to induction (59\%). In both groups PROM was the indication of induction in maximum cases (41\%).Table 2, shows that in the present study $56.89 \%$ primigravidae in sublingual group were delivered with $50 \mu \mathrm{g}$ misoprostol (single dose) compared to $32.69 \%$ in vaginal group, which was statistically significant $(p<0.05)$. Table 3 , shows that in sublingual group majority of women (37.5\%) delivered within 8-12hrs, whereas in vaginal group $35.84 \%$ women delivered within 12-16hrs.As shown in Table 4, no significant difference seen between both the study groups in term of mode of delivery, need of oxytocin augmentation, intrapartum complications and fetal outcome. Table 5, shows Comparison of maternal and perinatal outcome to induction delivery interval. 
Table 1: Distribution of cases according to demographic profile and indications of induction

\begin{tabular}{|l|c|c|}
\hline Variable & Sublingual group $(\mathrm{s} / \mathrm{l})(\mathrm{n}=100)$ & Vaginal group(p/v) $(\mathrm{n}=100)$ \\
\hline Booked cases & 39 & 42 \\
\hline Unbooked cases & 61 & 58 \\
\hline Age group & $20-35$ & $20-35$ \\
\hline Primigravidae & 65 & 61 \\
\hline Miultipara & 35 & 39 \\
\hline Modified Bishop's score $\leq 3$ & 60 & 58 \\
\hline Modified Bishop's score $\geq 3$ & 40 & 42 \\
\hline Indications of induction & 44 & 38 \\
\hline PROM/Leaking & 27 & 30 \\
\hline Postdatism & 10 & 12 \\
\hline Hypertensive disorders in Pregnancy & 12 & 10 \\
\hline Oligohydramnios & 6 & 8 \\
\hline IUGR & 1 & 2 \\
\hline Others & & \\
*Gestational thrombocytopenia & & \\
Gestational Diabetes &
\end{tabular}

Table 2: Distribution according to total dose required for vaginal delivery

\begin{tabular}{|l|c|c|c|c|}
\hline \multirow{2}{*}{$\begin{array}{l}\text { Induction } \\
\text { delivery } \\
\text { dose }\end{array}$} & \multicolumn{2}{|c|}{ Sublingual group(n=88) } & \multicolumn{2}{c|}{ Vaginal group (n=81) } \\
\cline { 2 - 5 } & $\begin{array}{c}\text { Primigravida } \\
(\mathrm{n}=58)\end{array}$ & $\begin{array}{c}\text { Miultipara } \\
(\mathrm{n}=30)\end{array}$ & $\begin{array}{c}\text { Primigravida } \\
(\mathrm{n}=52)\end{array}$ & $\begin{array}{c}\text { Miultipara } \\
(\mathrm{n}=29)\end{array}$ \\
\hline $25 \mu \mathrm{g}$ & $3(5.17 \%)$ & $15(50.0 \%)$ & $1(11.92 \%)$ & $11(37.93 \%)$ \\
\hline $50 \mu \mathrm{g}$ & $33(56.89 \%)$ & $9(30.0 \%)$ & $17(32.69 \%)$ & $9(31.03 \%)$ \\
\hline $75 \mu \mathrm{g}$ & $7(12.06 \%)$ & $5(16.67 \%)$ & $14(26.92 \%)$ & $6(20.68 \%)$ \\
\hline $100 \mu \mathrm{g}$ & $10(17.24 \%)$ & $1(3.33 \%)$ & $12(23.07 \%)$ & $3(10.34 \%)$ \\
\hline $125 \mu \mathrm{g}$ & $3(5.17 \%)$ & - & $5(9.61 \%)$ & - \\
\hline$\geq 150 \mu \mathrm{g}$ & $2(3.44 \%)$ & - & $3(5.76 \%)$ & - \\
\hline
\end{tabular}

Table 3: Distribution of cases according to induction delivery interval

\begin{tabular}{|l|c|c|c|c|}
\hline Induction delivery interval & \multicolumn{2}{|c|}{ Sublingual group(n=88) } & \multicolumn{2}{c|}{ Vaginal group(n=81) } \\
\hline$<4 \mathrm{hrs}$ & 3 & $3.49 \%$ & 5 & $6.17 \%$ \\
\hline $4-8 \mathrm{hrs}$ & 14 & $14.9 \%$ & 10 & $12.33 \%$ \\
\hline $8-12 \mathrm{hrs}$ & 33 & $37.5 \%$ & 26 & $32.09 \%$ \\
\hline $12-16 \mathrm{hrs}$ & 22 & $25 \%$ & 29 & $35.80 \%$ \\
\hline $16-20 \mathrm{hrs}$ & 6 & $6.81 \%$ & 4 & $4.93 \%$ \\
\hline $20-24 \mathrm{hrs}$ & 6 & $6.81 \%$ & 4 & $4.93 \%$ \\
\hline$>24 \mathrm{hrs}$ & 4 & $4.54 \%$ & 3 & $3.7 \%$ \\
\hline
\end{tabular}

Table: 4 Distribution of cases according to mode of delivery, oxytocin augmentation, intrapartum complications and fetal outcome.

\begin{tabular}{|l|c|c|c|}
\hline \multicolumn{2}{|c|}{ Variable } & $\begin{array}{c}\text { Sublingual group(s/l) } \\
(\mathrm{n}=100)\end{array}$ & $\begin{array}{c}\text { Vaginal group(p/v) } \\
(\mathrm{n}=100)\end{array}$ \\
\hline \multirow{2}{*}{ Mode of delivery } & Vaginal & $88(88 \%)$ & $81(81 \%)$ \\
\cline { 2 - 4 } & Caesarean section & $12(12 \%)$ & $19(19 \%)$ \\
\hline \multirow{2}{*}{$\begin{array}{l}\text { Oxytocin } \\
\text { augmentation }\end{array}$} & Required & $33(33 \%)$ & $43(43 \%)$ \\
\hline \multirow{3}{*}{ Fetal complications } & Not required & $67(67 \%)$ & $57(57 \%)$ \\
\cline { 2 - 4 } & MSL & $9(40.09 \%)$ & $17(45.94 \%)$ \\
\cline { 2 - 4 } & Fetal & $3(13.63 \%)$ & $4(10.81 \%)$ \\
\hline \multirow{2}{*}{$\begin{array}{l}\text { Maternal } \\
\text { complications }\end{array}$} & Distress & $5(22.72 \%)$ & $4(10.81 \%)$ \\
\cline { 2 - 4 } & Hyperstimiulation & $2(9.09 \%)$ & $5(13.51 \%)$ \\
\hline Failed induction & APH & $1(4.54 \%)$ & $2(5.4 \%)$ \\
\hline \multirow{2}{*}{ Fetal outcome } & DTA & - & $2(5.4 \%)$ \\
\cline { 2 - 4 } & Cervical tear & $2(9.09 \%)$ & $3(8.1 \%)$ \\
\cline { 2 - 4 } & Apgar <7 at 1 min & $84(84 \%)$ & $23(77 \%)$ \\
\cline { 2 - 4 } & NICU Admission & $16(16 \%)$ & $7(7 \%)$ \\
\hline
\end{tabular}


Table: 5 Comparison of maternal and perinatal outcome to induction delivery interval

\begin{tabular}{|c|c|c|c|c|c|}
\hline \multirow{2}{*}{ Outcome } & \multicolumn{4}{|c|}{ Induction delivery interval } & \multirow{2}{*}{$\begin{array}{c}\begin{array}{c}\text { Total } \\
(\mathrm{n}=200)\end{array} \\
\text { No }\end{array}$} \\
\hline & $\leq 4-8 \mathrm{hrs}$ & $8-12 \mathrm{hrs}$ & $12-16 \mathrm{hrs}$ & $>16-20 \mathrm{hrs}$ & \\
\hline Abnormal uterine action & 7 & 2 & - & - & 9 \\
\hline Sublingual group & 4 & 1 & - & - & 5 \\
\hline Vaginal group & 3 & 1 & - & - & 4 \\
\hline \multicolumn{6}{|c|}{$\chi^{2}=0.032 \quad p=0.857 \quad$ Not Significant } \\
\hline Vaginal delivery & 32 & 59 & 51 & 27 & 169 \\
\hline Sublingual group & 17 & 33 & 22 & 16 & 88 \\
\hline Vaginal & 15 & 26 & 29 & 11 & 81 \\
\hline \multicolumn{6}{|c|}{$\chi^{2}=2.557 \quad p=0.465 \quad$ Not Significant } \\
\hline Caesarean section & 8 & 12 & 6 & 5 & 31 \\
\hline Sublingual group & 4 & 5 & 1 & 2 & 12 \\
\hline Vaginal & 4 & 7 & 5 & 3 & 19 \\
\hline
\end{tabular}

\section{Discussion}

In the present study maximum induced women were delivered vaginally $(87 \%$ in $\mathrm{s} / 1 \mathrm{v} / \mathrm{s} 79 \%$ in $\mathrm{p} / \mathrm{v}$ group). Caesarean sections were needed, $12 \%$ in $\mathrm{s} / \mathrm{l}$ and $19 \%$ in $\mathrm{p} / \mathrm{v}$ group compare to study by Caliskan et al found $81.3 \%$ delivered vaginally and $18.7 \%$ by Caesarean section in sublingual group. ${ }^{5}$ Bartusevicus et al found $17 \%$ Caesarean section in sublingual and $20 \%$ in vaginal group. ${ }^{6}$ Whereas study done by Nasar et al found Caesarean section rate of $35.2 \%$ in sublingual and $28.2 \%$ in vaginal group which was almost twice more than our study. ${ }^{7}$

In sublingual group maximum (56.89\%) primigravidae delivered with $50 \mu \mathrm{g}$ (single dose) Misoprostol, whereas with same dose in vaginal group $32.69 \%$ women delivered which is almost two times more in sublingual group and statistically significant. Similar number of women delivered in both groups up to $100 \mu \mathrm{g}$ dose. These above observations may be because of the systemic bioavailability of sublingual misoprostol avoided first pass metabolism; hence single dose was sufficient while in vaginal instillation the vaginal secretions decrease local effect of drug. In the study miultigravida women required less dose of drug for delivery due to favorable Bishop's score. Hence it is evident that single dose of misoprostol can be used for inducing the contraction and formation of lower uterine segment (without compromising the fetus) for betterment of surgery and maternal outcome during Caesarean section. Similarly, single dose can be used as trial for vaginal delivery in women for conditions as relative indications for caesarean section. In study of Bartusevicius et al mean number of doses of $50 \mu \mathrm{g}$ misoprostol was significantly lower in sublingual group. ${ }^{6}$

In present study out of all vaginal deliveries approximately $96 \%$ women delivered within $21 \mathrm{hrs}$ of induction in both groups, in s/l group maximum $(31.5 \%)$ delivered within $8-12 \mathrm{hrs}$ induction delivery interval. Whereas in vaginal group more (35.8\%) women delivered in 12-16hrs induction delivery interval. Similarly, in the study by Caliskan et al mean induction delivery interval in sublingual group was $11.8 \pm 7 \mathrm{hrs}$ and $12.4 \pm 6 \mathrm{hrs}$ in vaginal group. ${ }^{5}$ Study by Bartuseviucius et al it was $15 \mathrm{hrs}$ in sublingual and $16.7 \mathrm{hrs}$ in vaginal group. ${ }^{6}$

As showed in the study oxytocin augmentation was needed $33 \%$ in sublingual group compare to $43 \%$ in vaginal group. Similarly, study done in 2006 by Feitosa et al found that $34.6 \%$ cases in sublingual group needed augmentation. ${ }^{8}$ In contrast study by Nassar et al, $81.1 \%$ cases in sublingual group needed augmentation. ${ }^{7}$

In our study intrapartum maternal and fetal complications occurred in $22 \%$ sublingual and $47 \%$ vaginal group. Most common complication was MSL, which was $9 \%$ in sublingual and $17 \%$ in vaginal group. In sublingual group out of 9 cases of MSL 6 were delivered vaginally and 3 needed caesarean section, whereas in vaginal 
group out of 17 cases of MSL 11 were delivered vaginally and 6 underwent in caesarean section due to unfavorable cervix. Similarly, in study by Fisher et al, more MSL were found in vaginal group $(7.8 \%)$ then in sublingual group $(1.6 \%){ }^{9}$ Hyperstimiulation was found in 4 women in sublingual and 3 women in vaginal group. Out of them one in vaginal group was managed by tocolytics ( $\mathrm{s} / \mathrm{c}$ Inj. terbutaline), all other were taken for caesarean section due to abnormal fetal heart rate. Study done by Bartusevicius et al found similar rate of hyperstimiulation in both groups. ${ }^{6}$ Feitosa et al found hyperstimiulation in $7 \%$ sublingual and $1.3 \%$ vaginal group. ${ }^{8}$ In contrast Moreas Filho found more hyperstimiulation in vaginal group i.e. $1.7 \%$ in sublingual Vs $3.2 \%$ in vaginal group. ${ }^{10}$ Tachysystole occurred in one cases of each group, which was managed by tocolytics with subcutaneous injection terbutaline. ${ }^{10}$

In present study caesarean section for failed induction was done in $2 \%$ cases of sublingual and $3 \%$ cases of vaginal group. Study by Nassar et al, found $3.5 \%$ failed induction in each group. ${ }^{7}$ Bartusevicius et al, found same rate of induction failure in both groups. ${ }^{6}$ In contrast study by Moreas Filho et al found more failed induction in sublingual group i.e. $10.3 \%$ sublingual Vs $4.8 \%$ in vaginal group. $^{10}$

In our study $84 \%$ in sublingual and $77 \%$ in vaginal group had healthy baby at the time of delivery. In sublingual group $16 \%$ babies had Apgar $<7$ at $1 \mathrm{~min}$, out of them $11 \%$ needed resuscitation and $5 \%$ were admitted in NICU. Whereas, in vaginal group 23\% babies had Apgar $<7$ at $1 \mathrm{~min}$, out of the $17 \%$ needed resuscitation and $7 \%$ were admitted in NICU, but there was no still birth and all NICU admitted babies were discharge in good condition. In the study by Moreas Filho et al, Apgar $<7$ at 1 min found in $3.5 \%$ babies in sublingual and $4.8 \%$ in vaginal group. ${ }^{10}$

In our study when induction delivery interval is compared, in sublingual group $17 \%$ women delivered within $8 \mathrm{hrs}$ of induction with less dose, but during this interval maximum cases $75.0 \%$ (3/4) with hyperstimiulation syndrome were noted. In these cases, early decision of caesarean section was taken as associated with high risk factors i.e. postdatism, IUGR, oligohydramnions. This may be due to early rise in plasma level of drug or repetition of drug prior to subside of its first dose plasma level. Thus 25\% (4/12) caesarean section were done in this period and $18.75 \%(3 / 16)$ babies had Apgar $<7$ at $1 \mathrm{~min}$ and one baby admitted in NICU. Whereas, in vaginal group within $8 \mathrm{hrs}$ of induction $15 \%$ cases delivered vaginally and $21.0 \%$ (4/19) needed caesarean section same as sublingual group maximum hyperstimiulation syndrome $66.6 \%$ $(2 / 3)$ occurred in this period $17.39 \%$ (4/23) babies had Apgar $<7$ at $1 \mathrm{~min}$ and $28.5 \%$ (2/7) needed NICU admission. In $8-12 \mathrm{hrs}$ of induction in sublingual group maximum (37\%) women delivered vaginally and $41.67 \%(5 / 12)$ needed caesarean section, which were mostly due to MSL (2/12) or fetal distress (2/12). These babies (6/13) had Apgar $<7$ at 1 min out of them 3 needed NICU admission. In vaginal group maximum caesarean section $36.84 \%$ (7/19) were done in this period, out of them mostly (6/7) were due to MSL and fetal distress. These babies were also compromised and 43.4\% (10/23) babies had Apgar $<7$ at $1 \mathrm{~min}$ and 2 were needed NICU admission. After $16 \mathrm{hrs}$ of induction caesarean sections for failed induction were done in 2 women in sublingual and 3 women in vaginal group.

\section{Conclusion}

The secret of success in labor induction lies on replicating the process of spontaneous parturition as closely as possible. Cervical ripening is a prelude to onset of myometrial contractions. Misoprostol administered sublingually as compared to vaginally has been proved to be an effective and better method for cervical ripening and induction of labor, when combined with judiciously timed amniotomy achieving more 
vaginal deliveries in women with unfavorable cervix.

But the benefits necessitate to be carefully balanced against the risk of adverse neonatal outcome due to uterine hyperstimiulation, which was observed more in initial hours of induction. There was no significant difference in both groups with respect to mode of delivery, induction delivery interval, abnormal uterine action, failed induction and neonatal outcome, bearing in mind that our sample size was not powered to evaluate these parameters for safety. However sublingual dose is attractive because of ease of administration, less frequent need for vaginal examinations, greater freedom of position, possibility of its use despite vaginal bleeding or leaking, less dose and induction delivery interval required for vaginal delivery. In conclusion Misoprostol seems to be relatively safe, cheap, easy to administer and quite effective for successful induction of labor which is boon to women of developing countries.

\section{Financial Support for the Research: Nil Conflicts of Interest Statement: Nil}

\section{References}

1. Goldberg $\mathrm{AB}$, Wing $\mathrm{DA}$, Induction of labor: the misoprostol controversy. $J$. Midwifery womens Health 2003:48:244-8.

2. Marguliesm.Campos Perez G;voto LS. Misoprostol to induce labor. Lancet 1992; 339:64

3. HOPC, Ngai SW, Liu KL, GCY, Lee SW, Vaginal misoprostol compared with oral misoprostol in termination of second trimester pregnancy. Obstet Gynecol 1997; 90:735-8

4. Khan RU, EL Refaey H, Sharma S, Sooranna D, Stafford M. Oral, rectal and vaginal pharmacokinetics of misoprostol. Obstet Gynecol 2004; 103;866-70

5. Caliskan E, Bodur H, Ozeren S, Corakci A et al: Misoprostol 50mg sublingually versus vaginally for labor induction at term. Gynaecol Obstet Invest 2005; 59:155-61.

6. Bartusevicius, A., Barcaite, E., Krikstolaitis, R., Gintautas, V. and Nadisauskiene, R. (2006), Sublingual compared with vaginal misoprostol for labour induction at term BR. J. OBS GYN An Internal Journal of Obs Gyn 113:14310528.

7. Nassar AH, Awwad J, Khalil AM, Abu Musa A. et al: A randomized comparison of patient satisfaction with vaginal and sublingual misoprostol for induction of labor at term. BJOG 2007; 114:1215-21

8. Feitosa FEL, Sampaio ZS, Alencar Ca Jr et al: Sublingual versus vaginal misoprostol for induction of labor. Int $J$ Gynaecol Obstet 2006; 94:91-5.

9. Stephanie A. Fisher, V. Paul Mackenzie, Gregory A.L. Davies. Oral versus vaginal misoprostol for induction of labor: A double-blind randomized controlled trial. American Journal of Obstetrics \& Gynecology 2001 Oct;185(4): 906-10.

10. Moraes Filho OB, Albuquerque RM, Pacheco AJC et al: Misoprostol sublingual versus vaginal para inducao do parto a termo. Rev Bras Ginocol Obstet 2005; 27: 24-31. 